\title{
Synchronous Reluctance Motor Performance Based on Different Electrical Steel Grades
}

\author{
M. N. Ibrahim ${ }^{1,2}$, Student Member IEEE, Peter Sergeant ${ }^{1}$, Member IEEE, and E. M. Rashad ${ }^{3}$, Senior Member IEEE \\ ${ }^{1}$ Department of Electrical Energy, Systems and Automation, Ghent University, Ghent 9000, Belgium \\ ${ }^{2}$ Electrical Engineering Department, Kafrelshiekh University, Kafr el-Sheikh 33511, Egypt \\ ${ }^{3}$ Electrical Power and Machines Department, Tanta University, Tanta 31527, Egypt
}

This paper investigates the influence of various electrical steel grades on the torque and efficiency of synchronous reluctance motors (SynRMs). Four different steel grades are studied for the same motor geometry. A finite-element method is combined with an experiment-based magnetic material model to study the effect of the four steel grades on the performance of the SynRM. On the one hand, there is a negligible effect on the torque ripple because this ripple depends mainly on the motor geometry. On the other hand, it was found that the material properties have an obvious effect on the SynRM efficiency and output power. Evidently, the low loss grades result in higher efficiency: 9\% point higher for NO20 compared with M600-100A. One of the four considered grades is designed to have a higher flux density in the useful magnetic field range (a few hundreds to a few thousand amperes per meter). This grade has somewhat lower efficiency, but results in a higher saliency ratio and an $8 \%$ higher torque output compared with the worst grade. Some experimental validation results are shown.

Index Terms-Electrical steel grade, finite-element method (FEM), synchronous reluctance motor (SynRM).

\section{NOMENCLATURE}

$i_{d}, i_{q} \quad$ Direct- and quadrature-axis stator currents, respectively (A).

$L_{d}, L_{q}$ Direct- and quadrature-axis stator inductances of the SynRM, respectively $(\mathrm{H})$.

$P \quad$ Number of pole pairs.

$p \quad$ Differential operator $(d / d t)$.

$R_{S} \quad$ Stator resistance of SynRM $(\Omega)$.

$T_{e} \quad$ Electromagnetic torque of the motor $(\mathrm{N} \cdot \mathrm{m})$.

$V_{d}, V_{q}$ Direct and quadrature components of the stator voltages, respectively $(\mathrm{V})$.

$V_{m} \quad$ Maximum input voltage of the motor $(\mathrm{V})$.

$I_{m} \quad$ Maximum input current of the motor (A).

$\delta, \alpha \quad$ Load angle and current angle, respectively (rad).

$\omega_{r}, \omega_{s}$ Motor and synchronous speeds, respectively ( $\left.\mathrm{rad} / \mathrm{s}\right)$.

$B \quad$ Magnetic flux density (T).

$H \quad$ Magnetic field intensity $(\mathrm{A} / \mathrm{m})$.

$\theta_{r} \quad$ Rotor position $\left({ }^{\circ}\right)$.

\section{INTRODUCTION}

$\mathbf{R}$ ECENTLY, the synchronous reluctance motor (SynRM) has received more attention for many applications, thanks to its rugged construction and the absence of rare-earth magnets. Another important feature of the SynRM is that the rotor is potentially less expensive than the rotor of both permanent magnet synchronous machines (PMSMs) and induction machines (IMs) due to the absence of both cage windings and magnets. The torque per ampere is acceptable compared with those of PMSMs and IMs [1]. The SynRM rotor can withstand high temperatures as well as high centrifugal forces due to its robust construction. Moreover, the control system is similar

Manuscript received March 19, 2015; revised May 12, 2015; accepted June 1, 2015. Date of publication June 4, 2015; date of current version October 22, 2015. Corresponding author: M. N. Ibrahim (e-mail: m.nabil@eng.kfs.edu.eg).

Color versions of one or more of the figures in this paper are available online at http://ieeexplore.ieee.org.

Digital Object Identifier 10.1109/TMAG.2015.2441772 to that of IM drives. However, rotor position information is necessary [1], [2].

Over the past decade, developments in machine design methodology, high-quality magnetic materials, and advanced power electronics have allowed the machine designers to enhance the performance of the SynRM. The performance of a SynRM mainly depends on the direct- and quadrature-axis inductances $\left(L_{d}, L_{q}\right)$ that are affected by the rotor geometry. Therefore, considerable attention has been given to improve the saliency ratio of the SynRM, taking into account the core material and its saturation behavior [3].

Several papers have focused on the rotor geometry design and the saturation effect on the performance of the SynRM [3]-[6]. However, the effect of the electrical steel grades on the performance of SynRM has not been deeply studied.

This paper investigates the influence of different types of electrical steel grades on the performance of the SynRM. Finite-element method (FEM) is combined with an experiment-based magnetic material model to study the behavior of the motor based on the different steel grades.

\section{SynRM MODELLING}

\section{A. Mathematical $d-q$ Model of the SynRM}

The $d-q$ model of a SynRM can be represented in the rotor reference frame, which rotates at $\omega_{r}$ [6], [7], so that voltage equations are given by

$$
\begin{aligned}
& V_{d}=R_{s} i_{d}+p \lambda_{d}\left(i_{d}, i_{q}\right)-\omega_{r} P \lambda_{q}\left(i_{d}, i_{q}\right) \\
& V_{q}=R_{s} i_{q}+p \lambda_{q}\left(i_{d}, i_{q}\right)+\omega_{r} P \lambda_{d}\left(i_{d}, i_{q}\right) .
\end{aligned}
$$

The $d q$-axis flux linkage relations are expressed as

$$
\lambda_{d}\left(i_{d}, i_{q}\right)=L_{d}\left(i_{d}, i_{q}\right) i_{d}, \quad \lambda_{q}\left(i_{d}, i_{q}\right)=L_{q}\left(i_{d}, i_{q}\right) i_{q} .
$$

The electromagnetic torque can be obtained as

$$
T_{e}=\frac{3}{2} P\left(\lambda_{d}\left(i_{d}, i_{q}\right) i_{q}-\lambda_{q}\left(i_{d}, i_{q}\right) i_{d}\right) .
$$




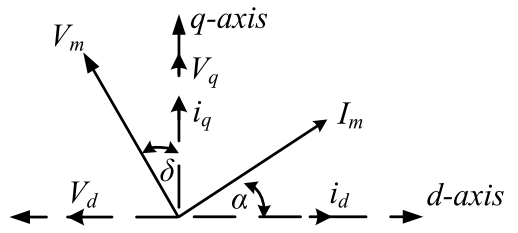

Fig. 1. Current and voltage diagrams.

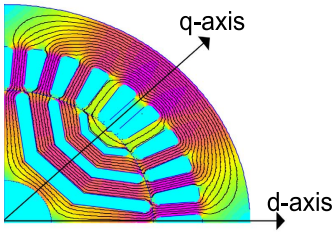

(a)

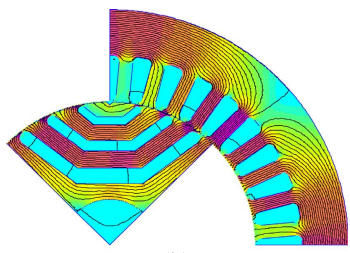

(b)
Fig. 2. Flux paths for a SynRM using the FEM for a quarter geometry. (a) $\theta_{r}=0^{\circ}$. (b) $\theta_{r}=45^{\circ}$.

The $d q$-axis currents can be expressed as a function of the current angle $(\alpha)$

$$
i_{d}=I_{m} \cos (\alpha), \quad i_{q}=I_{m} \sin (\alpha)
$$

where $\alpha$ is the angle of the stator current space vector with respect to the $d$-axis of the motor, as shown in Fig. 1.

The $d q$-axis supply voltage can be expressed as follows:

$$
V_{d}=-V_{m} \sin (\delta), \quad V_{q}=V_{m} \cos (\delta)
$$

where $\delta$ is the machine load angle as shown in Fig. 1.

Neglecting the stator resistance $R_{S}$, the power factor (PF), and the maximum power factor (MPF) of the SynRM can be expressed as a function of the saliency ratio $K=L_{d} / L_{q}$ [8]

$$
\mathrm{PF}=\frac{K-1}{\sqrt{K^{2} \frac{1}{\sin ^{2}(\alpha)}+\frac{1}{\cos ^{2}(\alpha)}}}, \quad \mathrm{MPF}=\frac{K-1}{K+1} .
$$

The torque ripple can be calculated as follows:

$$
T_{\text {ripple }}=\frac{\max \left(T_{e}\right)-\min \left(T_{e}\right)}{\operatorname{avg}\left(T_{e}\right)}
$$

where max, min, and avg are the maximum, the minimum, and the average values of the electromagnetic torque, respectively.

\section{B. Finite Element Method Model of the SynRM}

The electromagnetic torque can be calculated using the Maxwell stress tensor method. This method is applied at a radius $(r)$ that is at the center of the air gap. It can be expressed as follows [9]:

$$
T_{e}=\frac{1}{\mu_{o}} \int_{0}^{\frac{\pi}{2}} r^{2} B_{r} B_{\theta} d \theta
$$

where $B_{r}$ and $B_{\theta}$ are the radial and tangential components of the flux density $B$, respectively.

The SynRM has four poles with symmetrical geometry. Therefore, it is preferable to model a quarter of the motor geometry to reduce the time of calculation. Fig. 2 shows the quarter of the motor geometry using the FEM for flux paths.
TABLE I

PROTOTYPE SynRM GEOMETRICAL AND EleCtromagnetic PARAMETERS

\begin{tabular}{|l|c|l|c|}
\hline \multicolumn{1}{|c|}{ Parameter } & Value & \multicolumn{1}{c|}{ Parameter } & Value \\
\hline $\begin{array}{l}\text { Number of rotor flux } \\
\text { barriers per pole }\end{array}$ & 3 & $\begin{array}{l}\text { Rotor shaft } \\
\text { diameter }\end{array}$ & $35 \mathrm{~mm}$ \\
Number of pole pairs & 4 & Axial length & $140 \mathrm{~mm}$ \\
Number of stator slots & 36 & Air gap length & $0.3 \mathrm{~mm}$ \\
Number of phases & 3 & Rated speed & $6000 \mathrm{RPM}$ \\
Stator outer diameter & $180 \mathrm{~mm}$ & Rated frequency & $200 \mathrm{~Hz}$ \\
Stator inner diameter & $110 \mathrm{~mm}$ & Rated current & $22 \mathrm{~A}$ \\
Rotor outer diameter & $109.4 \mathrm{~mm}$ & Material grade & M400-50A \\
\hline
\end{tabular}

\section{Loss Model of the SynRM}

The iron losses of the SynRM can be calculated based on the statistical loss theory of Bertotti. The theory depends on loss separation into hysteresis, classical, and excess losses [9]

$$
\left.\begin{array}{l}
P_{\text {hyst }}=a_{M} B_{p}^{\alpha_{M}} f \\
P_{\text {class }}(t)=b_{M}\left|\frac{d B}{d t}\right|^{2} \\
P_{\text {exc }}(t)=c_{M}\left(\sqrt{1+d_{M}\left|\frac{d B}{d t}\right|}-1\right)\left|\frac{d B}{d t}\right| \\
P_{\text {iron }}=\left(P_{\text {hyst }}+P_{\text {class }}+P_{\text {exc }}\right) \rho
\end{array}\right\}
$$

where $a_{M}, \alpha_{M}, b_{M}, c_{M}, d_{M}$, and $\rho$ are the material-dependent parameters and $f$ is the frequency of the applied field.

On the other hand, the SynRM copper losses can be easily computed using the measured phase resistance as follows:

$$
P_{\mathrm{cu}}=3 I_{\mathrm{Ph}}^{2} R_{\mathrm{ph}} \text {. }
$$

The efficiency of the motor is given by

$$
\eta=\frac{P_{o}}{P_{o}+P_{\mathrm{cu}}+P_{\text {iron }}}
$$

where $P_{o}$ is the mechanical output power of the motor calculated using the computed torque from the FEM model by

$$
P_{o}=T_{e} \omega_{r}
$$

\section{RESUlts AND Discussion}

To investigate the effect of different magnetic materials on the performance of the SynRM, four steel grades M600-100A, M400-50A, M330P-50A, and NO20 are considered. These materials have different loss values and different thicknesses. A sample of simulation results is obtained using the geometrical and electromagnetic properties of the machine, which are described in Table I.

All the results are computed at the same current and speed that are the rated values of the SynRM. In addition, the same geometry, mesh nodes, and elements are considered. The number of nodes and elements of the FEM model are approximately 31238 and 56371, respectively.

Fig. 3 shows the magnetization characteristics of the four electrical steel grades. It is noted that M330P-50A has a higher flux density $(B)$ for magnetic fields $(H)$ higher than $250 \mathrm{~A} / \mathrm{m}$. Moreover, NO20 and M600-100A have the higher and lower permeabilities compared with the other materials for $H$ less than $250 \mathrm{~A} / \mathrm{m}$.

Fig. 4 shows the variation of $d$-axis and $q$-axis inductances for different current angles including the saturation and the cross magnetization effect (the effect of $d$-axis current on 

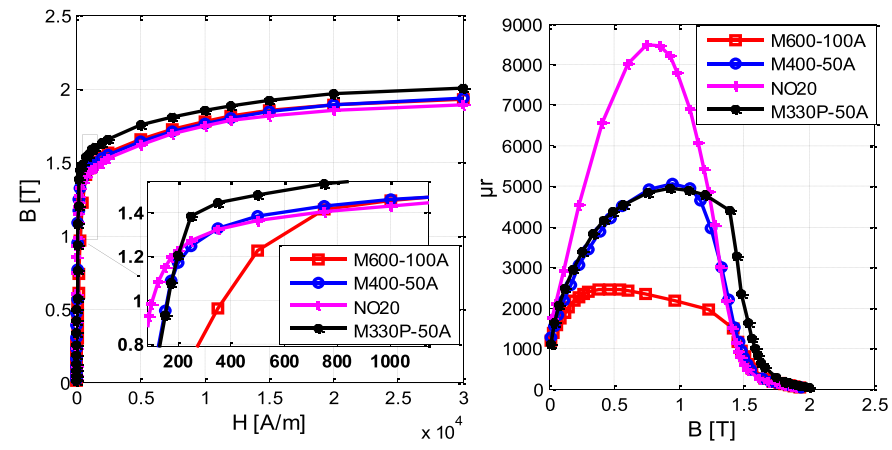

Fig. 3. Magnetization curves for different steel grades.
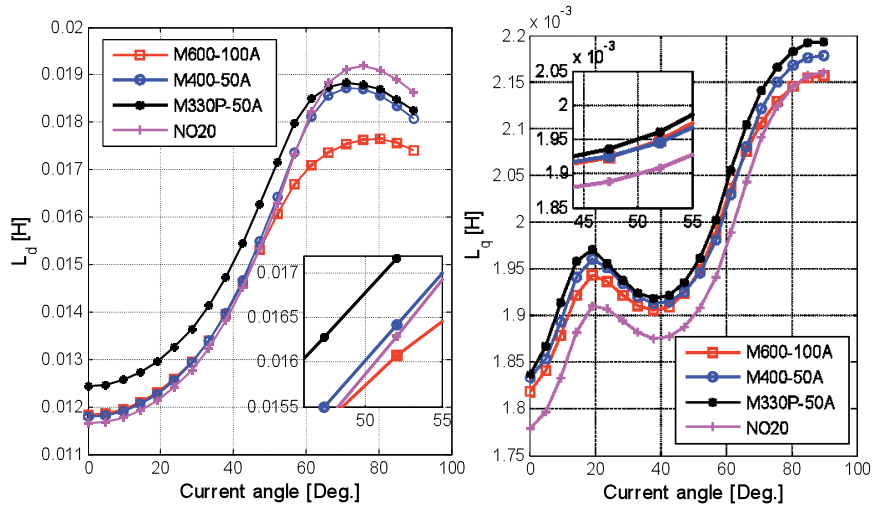

Fig. 4. $d q$-axis inductances of the SynRM with different current angles.

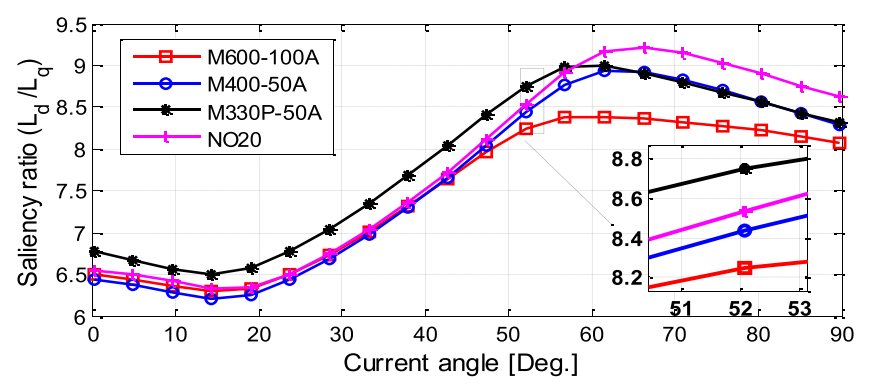

Fig. 5. Saliency ratio of the SynRM with different current angles.

$q$-axis flux linkage and vice versa). The current angle is the angle between the stator current space vector with respect to the $d$-axis of the motor. It can be noted that with different current angles, there is an obvious change in the $d q$-axis inductances for all the electrical steel grades. This is due to the different permeability of the materials.

Fig. 5 shows the variation of saliency ratio of the SynRM for different current angles. M330P-50A has the largest saliency ratio value compared with M600-100A that has the smallest value for a current angle less than the maximum power angle. This is due to different permeability between the materials which has a direct effect on the saliency ratio. The difference will make a variation on the performance of the motor, as described in Fig. 6. Fig. 6 shows the motor output power for different current angles. It can be seen that there is a difference in the output power for different materials. M330P-50A has the highest output power, which is about $8 \%$ higher than for M600-100A because it has the higher saliency ratio.

Fig. 7 shows the variation of the motor power factor due to different materials. It can be deduced from (7) that the

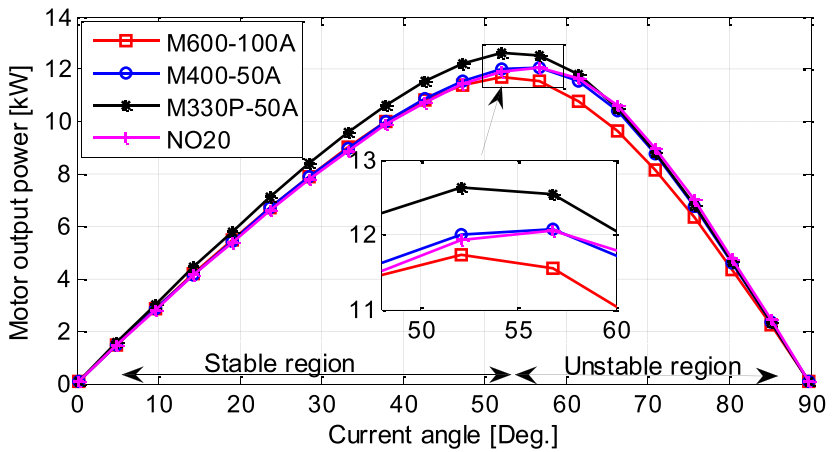

Fig. 6. Motor output power at $6000 \mathrm{r} / \mathrm{min}$ with different current angles.

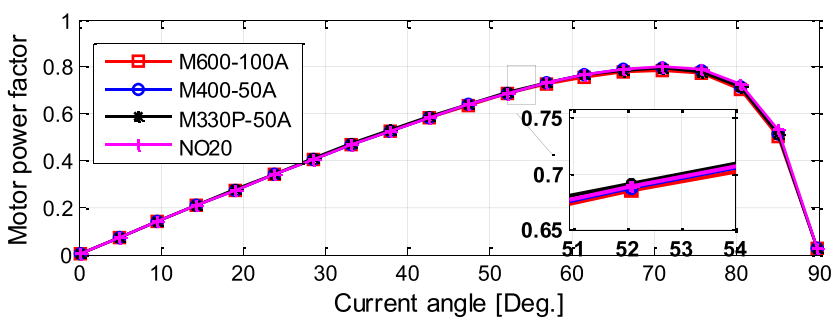

Fig. 7. Motor power factor with different current angles.

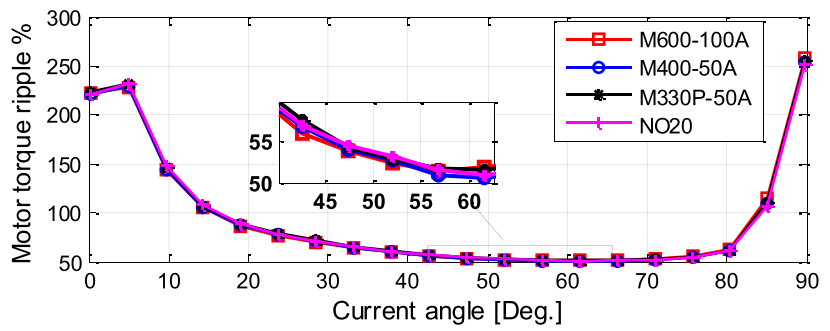

Fig. 8. Motor torque ripple (percent) with different current angles.
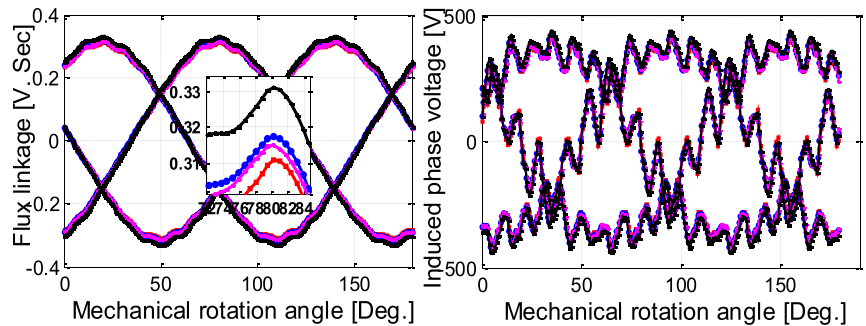

Fig. 9. Flux linkage and the induced phase voltage of the SynRM with mechanical rotation angle.

current angle has a higher effect on the power factor than the saliency ratio. Therefore, it is clear from Fig. 7 that the material grade has almost no influence on the power factor of the motor compared with the current angle that has a great influence on it. Fig. 8 shows the torque ripple of the SynRM with different current angles. It can be noted that there is no difference in the torque ripple between the different materials because the torque ripple mainly depends on the motor geometry that is the same. But the SynRM with the geometry under study has a high torque ripple. It is around $50 \%$ at the maximum torque angle.

Fig. 9 shows the flux linkage and the induced phase voltage of the SynRM for different steel grades. It is clear that M330P-50A and M600-100A have the highest and lowest flux linkage and induced voltage, respectively. This is due to saliency ratio difference. 
TABLE II

SynRM CHARACTERISTICS AT MAXIMUM TORQUE ANGLE

\begin{tabular}{|c|c|c|c|c|}
\hline \multirow{2}{*}{ Factor } & \multicolumn{4}{|c|}{ Steel Grade } \\
\cline { 2 - 5 } & NO20 & $\begin{array}{c}\text { M330P- } \\
\mathbf{5 0 A}\end{array}$ & $\begin{array}{c}\text { M400- } \\
\mathbf{5 0 A}\end{array}$ & $\begin{array}{c}\text { M600- } \\
\mathbf{1 0 0 A}\end{array}$ \\
\hline Iron loss $(\boldsymbol{W})$ & 221.2 & 667.5 & 527.7 & 1451 \\
\hline $\boldsymbol{P}_{\boldsymbol{o}}(\boldsymbol{k W})$ & 11.973 & 12.671 & 12.054 & 11.772 \\
\hline $\boldsymbol{\eta} \%$ & 96.567 & 93.560 & 94.2737 & 87.6681 \\
\hline $\boldsymbol{T}$. ripple \% & 51.34 & 50.72 & 50.58 & 50.05 \\
\hline$\left(\boldsymbol{L}_{\boldsymbol{d}}-\boldsymbol{L}_{\boldsymbol{q}}\right)(\boldsymbol{H})$ & 0.0144 & 0.0152 & 0.0145 & 0.0141 \\
\hline $\boldsymbol{P F}$ & 0.6870 & 0.6906 & 0.6867 & 0.6842 \\
\hline $\boldsymbol{T}_{\boldsymbol{o}}(\boldsymbol{N} . \boldsymbol{m})$ & 19.056 & 20.166 & 19.1849 & 18.7363 \\
\hline
\end{tabular}
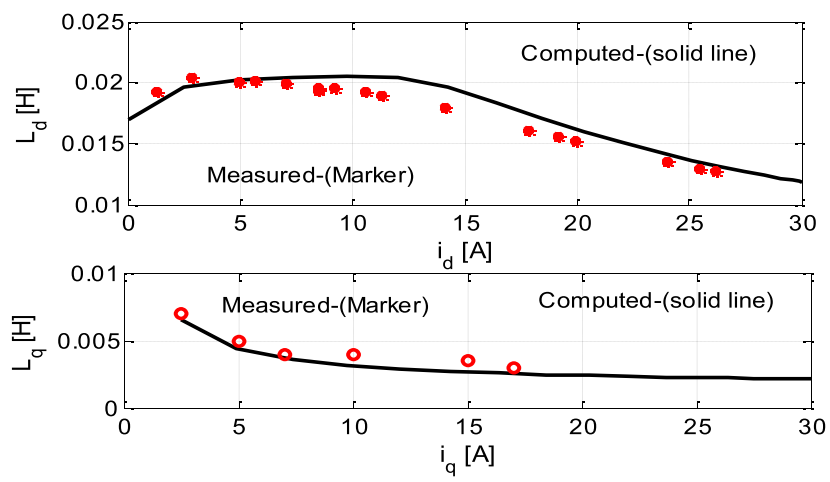

Fig. 10. Measured (markers) and computed (solid line) $d q$-axis inductances of the SynRM with different currents.

Table II summarizes the computed iron losses of the SynRM using the statistical loss theory of Bertotti at the maximum torque angle. This angle is approximately $52^{\circ}$ (see Fig. 6). Moreover, several characteristics for the SynRM are included in Table II. From Table II, it can be noted that NO20 gives the highest efficiency, which is about $9 \%$ point higher than for M600-100A. Moreover, the higher output power, torque, saliency ratio, and power factor can be achieved using $\mathrm{M} 330 \mathrm{P}-50 \mathrm{~A}$. This is due to the higher saliency ratio. The lower loss grades are more expensive both in raw material cost and in cutting cost. In a rough approximation, the lowest loss grade will have more or less double cost compared with the highest loss grade.

\section{EXPERIMENTAL VALIDATION}

To validate the computed results using the FEM analysis, some measurements for $L_{d}\left(i_{d}\right)$ and $L_{q}\left(i_{q}\right)$ are considered using the conventional VI method given in [10]. Fig. 10 shows the measured and computed $d q$-axis inductances for the SynRM that is built with M400-50A. It can be noted that the measured values have the same tendency as the simulations. They prove the nonlinearity on the inductance values that greatly affect the SynRM performance.

\section{CONCLUSION}

This paper has presented the influence of different electrical steel grades on the performance of a SynRM. Four different steel grades with different losses and thicknesses are studied. It has been found that the $d q$-axis inductances of the motor are affected by the material properties due to different permeabilities. Hence, the SynRM performance changes because it mainly depends on the saliency ratio. It was found that M330P-50A has the highest output power, which is about $8 \%$ higher than for M600-100A. In addition, the material grade has almost no influence on the power factor of the motor, but the current angle has a great influence on it. The SynRM with the geometry under study has a high torque ripple of around $50 \%$ at the maximum torque angle. In addition, it does not depend on the material properties because it mainly depends on the motor geometry.

Moreover, there is a notable effect on the iron loss and the efficiency of the SynRM. NO20 gives the highest efficiency, which is about 9\% higher than for M600-100A. On the other hand, M330P-35A has the highest output power, torque, saliency ratio, and power factor.

Finally, it can be concluded that the best steel grades of the studied materials are NO20 and M330P-50A, respectively. The higher permeability makes the material more favorable for the SynRM. The obtained simulation results prove the effectiveness of the electrical steel grade on the performance of the SynRM. Some experimental measurements are considered to validate the computed results.

\section{ACKNOWLEDGMENT}

This work was supported by the Egyptian Ministry of Higher Education (Cultural Affairs and Missions Sector) and Special Research Fund of Ghent University (BOF).

\section{REFERENCES}

[1] S. Taghavi and P. Pillay, "A sizing methodology of the synchronous reluctance motor for traction applications," IEEE J. Emerg. Sel. Topics Power Electron., vol. 2, no. 2, pp. 329-340, Jun. 2014.

[2] S. J. Mun, Y. H. Cho, and J. H. Lee, "Optimum design of synchronous reluctance motors based on torque/volume using finite-element method and sequential unconstrained minimization technique," IEEE Trans. Magn., vol. 44, no. 11, pp. 4143-4146, Nov. 2008.

[3] J. H. Lee, I. K. Lee, Y. H. Cho, and T. W. Yun, "Characteristics analysis and optimum design of anisotropy rotor synchronous reluctance motor using coupled finite element method and response surface methodology," IEEE Trans. Magn., vol. 45, no. 10, pp. 4696-4699, Oct. 2009.

[4] A. Vagati, M. Pastorelli, F. Scapino, and G. Franceschini, "Impact of cross saturation in synchronous reluctance motors of the transverselaminated type," IEEE Trans. Ind. Appl., vol. 36, no. 4, pp. 1039-1046, Jul./Aug. 2000.

[5] P. Lazari, B. Sen, J. Wang, and X. Chen, "Accurate $(d)-(q)$ axis modeling of synchronous machines with skew accounting for saturation," IEEE Trans. Magn., vol. 50, no. 11, Nov. 2014, Art. ID 8105704.

[6] M. Nabil, S. M. Allam, and E. M. Rashad, "Performance improvement of a photovoltaic pumping system using a synchronous reluctance motor," Electr. Power Compon. Syst. J., vol. 41, no. 4, pp. 447-464, Jan. 2013.

[7] Y.-S. Park, S.-M. Koo, S.-M. Jang, J.-Y. Choi, and D.-J. You, "Dynamic characteristic analysis of interior permanent magnet synchronous motor considering varied parameters by outer disturbance based on electromagnetic field analysis," IEEE Trans. Magn., vol. 50, no. 11, Nov. 2014, Art. ID 8202304

[8] T. Matsuo and T. A. Lipo, "Rotor design optimization of synchronous reluctance machine," IEEE Trans. Energy Convers., vol. 9, no. 2, pp. 359-365, Jun. 1994.

[9] A. Hemeida and P. Sergeant, "Analytical modeling of surface PMSM using a combined solution of Maxwell's equations and magnetic equivalent circuit," IEEE Trans. Magn., vol. 50, no. 12, Dec. 2014, Art. ID 7027913.

[10] S.-H. Hwang, J.-M. Kim, H. Van Khang, and J.-W. Ahn, "Parameter identification of a synchronous reluctance motor by using a synchronous PI current regulator at a standstill," J. Power Electron., vol. 10, no. 5, pp. 491-497, Sep. 2010. 